\title{
Provision of High-efficient Milling Methods Using a PMSM Electric Drive with a Controlled Information-Measuring System
}

\author{
Sergey Ambrosimov ${ }^{1}$,Victor Meshcheryakov, ${ }^{2, *}$, and Igor Ivshyn ${ }^{3}$ \\ ${ }^{1}$ Institute of Mechanical Engineering, Lipetsk State Technical University, Lipetsk, Russia \\ ${ }^{2}$ Electric Drive Department, Lipetsk State Technical University, Lipetsk, Russia \\ ${ }^{3}$ Department of Power supply of industrial enterprises, Kazan State Power Engineering University, Kazan, Russia
}

\begin{abstract}
The article presents new highly effective methods of milling shaped surfaces, which are implemented on four-and five-coordinate CNC machines. For their implementation, three simultaneously coordinated movements of the machine's organs are used. To implement the proposed milling methods on CNC machines, an electric drive is proposed, built on the basis of a Permanent Magnet Synchronous Motor (PMSM) with a vector control system with a proportional P-speed controller. For this purpose, an ecstatic control information and measurement system with zero static error is proposed. Comparative results of mathematical modeling of transient processes in electric drives with the standard and proposed control systems are presented.
\end{abstract}

\section{Introduction}

In mechanical engineering, controlled electric drive systems are widely used on CNC machines, while the requirements for drive and control systems are becoming more complex in terms of ensuring high speed and accuracy of working out control actions. In these conditions, AC electric drive systems based on a Permanent Magnet Synchronous Motor have proved to be the best.

An urgent problem in mechanical engineering is the search for ways to improve the efficiency of machining processes, increase labor productivity, tool life and cutting quality. Milling is one of the most productive processing methods due to the high concentration of cutting edges simultaneously involved in the cutting process, and at the same time high cost due to the high cost of equipment and tools. In addition, milling is associated with large volumes of cut material, especially when processing complex shaped surfaces, which affects the cost of the tool: disk shaped or end radius cutters.

One of the most effective ways to increase the durability of a cutting tool, as shown by recent research, is the constant displacement of the cutting edge tip during processing relative to the cutting surface, which leads to an increase in the active length of the cutting edge and a decrease in thermal stresses. For example, milling of a complex profile surface with convex sections of profiles such as Cams of couplings and gears is carried out with a tool with two conical producing surfaces that roll over the nominal surface of the part with nonlinear coordination between the three elementary movements of the workpiece (Fig. 1) [1]. One of them, the rotational $w \times 1$, is carried out in such a way that the straight forming tool is consistently tangent to each point of the processed profile, and the other two $\mathrm{Sz}$ and Sy agree with the rotational $\omega x 1$, so when processing cross sections of a straight profile, the forming rolls are applied to the workpiece.

The screw milling method is used for processing complex shallow narrow and wide grooves (Fig. 2) [2, $3]$. When milling wide grooves, the workpiece rotates around the $\mathrm{Y}$ axis and simultaneously moves in the direction of the $\mathrm{Y}$ axis until the nominal surface is reached and a lenticular surface area is selected. Then three movements are made simultaneously in the direction of rotation of the movement in the direction of the formation of the groove, i.e. $\mathrm{X}$ and $\mathrm{Z}$.

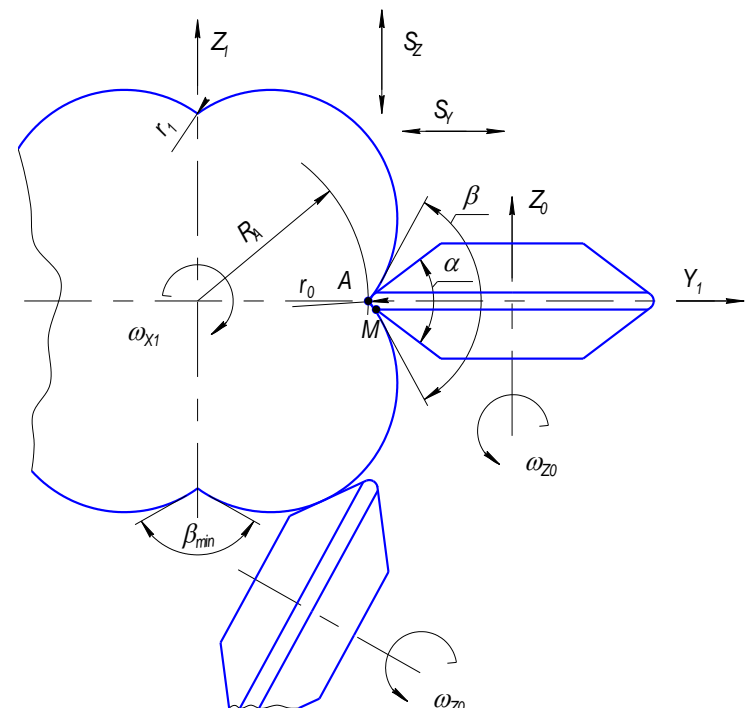

Fig. 1. Scheme of nonlinear rolling of a complex profile of a part with a complex mill.

\footnotetext{
* Corresponding author: mesherek@yandex.ru
} 


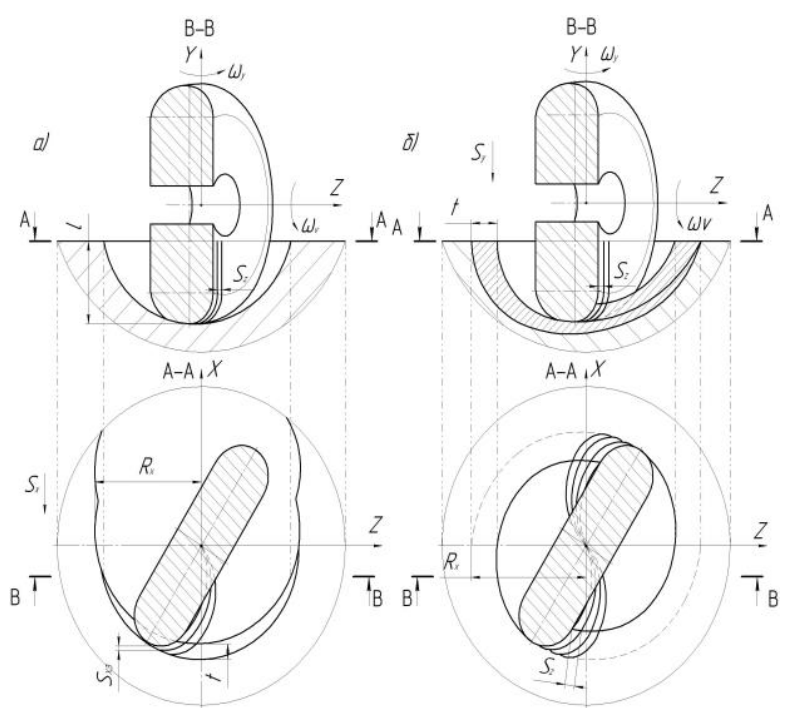

Fig. 2. The scheme of formation of the spiral groove for moving the cutter.

When milling narrow grooves, a lenticular area is formed after milling, which is bounded by the edges of the groove. The mill performs a relative reciprocating motion until the processing surface touches the sides of the groove, continuing to sink to its bottom. The advantage of this method is the displacement of the upper part of the cutting edge (CE) along the entire length of the $\mathrm{RC}$, starting from the right side of the cutter and ending with the left in one section. The cutting zone moves quite intensively relative to the $\mathrm{CE}$, providing a good heat sink and low thermal load on the cutting edges.

Theoretical studies have confirmed a significant increase in processing productivity and tool life due to an increase in the number of teeth simultaneously involved in the work, increasing the length of the cutting edges due to their constant displacement, i.e., the working contact of the vertices of the cutting teeth relative to the cutting surface.

$\mathrm{CNC}$ machines are currently widely used in engineering production for processing complex shaped surfaces, but their capabilities are already used by $10 \% \ldots$ $20 \%$, for example, when processing pockets of complex shapes, the end and disk radii of the cutters move along an equidistant surface, which significantly reduces the processing performance and tool life.

The developed milling methods require a fairly complex kinematics of forming-three or more complex coordinated movements of the machine's organs, and the movements are usually non-linearly coordinated, i.e. the quantitative ratio between individual movements changes, constantly obeying nonlinear laws. The provision of such kinematics is possible only with the use of $\mathrm{CNC}$ machine tools with four or five simultaneously controlled coordinates.

\section{Relay-vector control}

To ensure high performance of the machine drive, it is advisable to use a PMSM motor that has a minimum moment of inertia of the Rotor. An electric drive based on a PMSM motor with a vector control system with a proportional P-speed controller (Fig.1), provides typical transients when starting and adjusting the output coordinates of the drive.

At the same time, to implement the proposed highefficiency milling methods on CNC machines, it is advisable to perform an astatic system with zero static error and a reduction in over-regulation at the time of transition from the start-up mode to the steady-state mode. As a result of the research, a control system with a nonlinear speed controller (NLRS) and flexible speed feedback was developed, shown in Fig.3 with a dotted line.

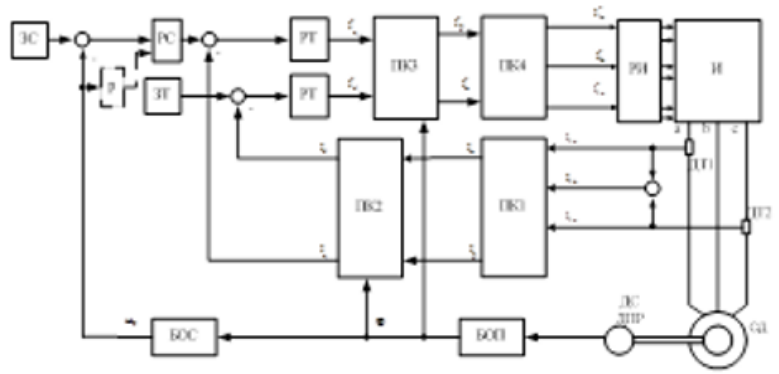

Fig. 3. Functional diagram of a PMSM electric drive.

\section{Vector control with sinusoidal PWM}

The results of mathematical modeling of transient processes in electric drives with standard and proposed control systems are shown in Fig. 4. the graphs show that the electric drive system with a nonlinear speed controller and flexible speed feedback is more suitable for use on $\mathrm{CNC}$ machines that implement the proposed innovative milling methods.

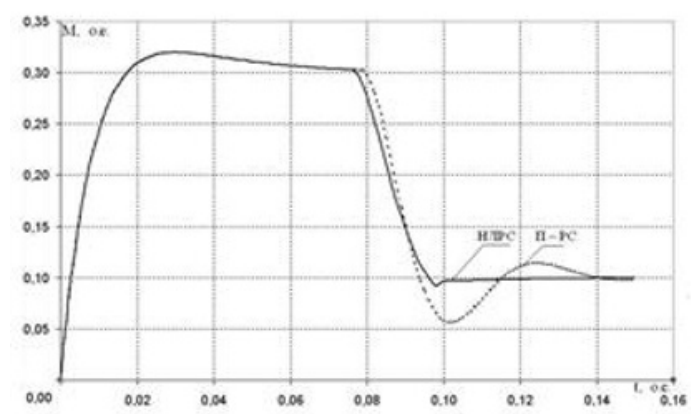

a)

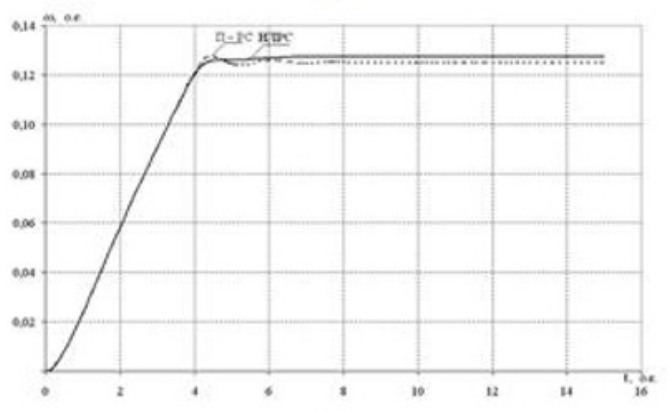

b)

Fig. 4. Comparative results of transient modeling: $a-M(t), b-$ $\omega(\mathrm{t})$ electric drive start mode. 


\section{Acknowledgements}

The paper was powered by research grant RFBR 19-48-480001 «Development, investigation and optimization of energysaving electrical and electrically driven automated systems for plasma, electrometal slag and induction technologies and units».

\section{References}

[1] S.K. Ambrosimov, A.A. Petrukhin, A method for processing curved surfaces, pat. no. 2167746 (RF), Byul., no. 15 (2001)

[2] S.K. Abrosimov, M.G. Sterkin, Method of processing shaped concave surfaces, pat. no. 22008502 (RF), Byul., no. 20 (2003)

[3] S.K. Ambrosimov, K.S. Ambrosimov, Method of screw black-and-white milling of shaped surfaces, pat. no. 2344023 (RF), Byul., no. 2 (2009)

[4] Y.I. Gracheva, O.V. Naumov, Evaluation criteria of contact group technical state concerning electrical appliances, International Journal of pharmacy and Technology 4, 27084-27091 (2016)

[5] Y.I. Gracheva, N.V. Chernova, A.I. Fedotov, E.A. Fedotov, Local Fourier transformation application for mathematic modeling of synchronous machine valve actuator, Journal of engineering and applied sciences 11, 1, 29392945 (2016)

[6] Y.I. Gracheva, O.V. Naumov, Operating Mode Influence on Probability Characteristics of Electric Devices, Journal of engineering and applied sciences 11, 1, 2934-2938 (2016)

[7] Y.I. Gracheva, O.V. Naumov, Evaluation criteria of contact group technical state concerning electrical appliances, Journal of engineering and applied sciences 11, 1, 26763-26770 (2016)

[8] Y.I. Gracheva, I.V. Ivshin, O.V. Naumov, A.N. Gorlov, D.D. Mitsu, Influence of resistance of contact units of switching devices on the electric power losses in shop networks of low tension, E3S Web of Conferences 124, 02013, SES-2019, 1-4 (2019)

[9] Y.I. Gracheva, V.N. Petrov, N.V. Russova, D.V. Samuilov, G.P. Svintsov, I.V. Protosovitsky, On modeling on a single-winding forced valve electromagnet in a circuit with a ballast resistor, E3S Web of Conferences 124, 02012, SES-2019, 5-9 (2019)

[10] Y.I. Gracheva, A.N. Alimova, Calculating Methods and Comparative Analysis of Losses of Active and Electric Energy in Low Voltage Devices, International Ural Conference on Electrical Power Engineering (UralCon), 361367 (2019)

[11] Y.I. Gracheva, A.N. Alimova, Calculating Probability of Faultless work of Shop Nets with the Help of Coefficients of Ratio, International
Russian Automation Conference (RusAutoCon), 3-6 (2019)

[12] V.N. Voyekov, V.N. Meshcheryakov, A vector control system of the valve electric drive on the basis of the independent inverter of tension with relay regulation of entrance current of the inverter and phase currents of the stator, Messenger YUURGU, Power series 17, 2, 48-57 (2017)

[13] V.N. Meshcheryakov, V.V. Danilov, Sh.R. Khasanov, S. Valtchev, Minimization of the stator current in induction motor with defined load on the shaft by maintaining optimum absolute slip, Kazan, SES 2019, E3S Web of Conferences, 01036 (2019)

[14] V.N. Meshcheryakov, D.V. Lastochkin, Z.M. Shakurova, S. Valtchev, Kazan, SES 2019, E3S Web of Conferences, 01037 (2019) 